\title{
Theoreticians thrive among dunes
}

\section{The Institute for Theoretical Physics at Santa Barbara has won itself an international reputation in just a decade, but the trick will not easily be repeated.}

\section{Santa Barbara, California}

THe Institute for Theoretical Physics here seems confident of an even more illustrious future than its immediate, but short, past. Just ten years old, the small permanent staff has had the luxury of interviewing architects during the past few weeks, with the intention of adding to its third request for a further five years of support from the National Science Foundation the cost of a building, which would be shared equally by the University of California at Santa Barbara. The signals from Washington are said to be encouraging; the Gramm-Rudmann Act might have been passed on another planet.

There is more than mere official encouragement to report, but the flattery of imitation as well. The present director of the centre, Dr Robert Schrieffer (the "S" of the BCS theory of classical superconductivity who was calumnously said, in Nature two years ago, to have taken a job in Wall Street) says that there have been serious inquiries about the reasons for Santa Barbara's success from people hoping to follow it in Europe. What follows is meant as a thumbnail explanation.

Part of the reason must be the setting, which everybody acknowledges to be a magnet for people from elsewhere. President Ronald Reagan's ranch is in the hills twenty miles north, near the Vandenburg Air Force Base, the back-up shuttle site. The institute is at present housed on the sixth floor of a building at the centre of the university campus established a quarter of a century ago. Although on the edge of the ocean, the campus huddles in the dunes as if afraid of the sea, but the new two-storey building will look directly over the Pacific.

The present members of the institute are anxious to emphasize the degree to which their success stems from their way of working, which in turn stems from the enthusiasm of the then much smaller university for a competition launched in 1968 by the National Science Foundation, which at the outset offered a subvention of $\$ 1$ million a year. Part of the calculation then was that the university's own physics department could only profit from the presence of a distinguished, but constantly changing, group of theoreticians. The calculation has been correct; the university's own theoretical physics group is now comparable in size and distinction with that at the institute.

The guiding principle is change. The permanent senior staff numbers just six, including the director and his deputy and a dozen or 15 postdoctoral workers. But the bread and butter of the institute's work consists of a series of overlapping scientific programmes, perhaps best described as workshops, which last for between 6 and 12 months and each bring 15 or so people to the site at any time. (But a programme on high- $T_{\text {c }}$ superconductivity due to begin next January and to last for six months is so heavily oversubscribed that it is not clear where everybody will sit.) The period is long enough for particpants to get serious work done during their stay, as well as to embark on collaborations with other visitors.

Schrieffer (whose five-year term as director will be up in time for him to be an ordinary participant in the superconductivity programme) insists on the care with which the topics of these studies are chosen. The objective, he says, is to find out what the "community" would like to spend six months or more upon, which he emphasizes is consistent with Santa Barbara's role as a national resource. The procedure is that topics are ultimately chosen by the rotating membership of the institute's external advisory board, itself a roster of the working great and good. The trick, Schrieffer says, is to find an able an enthusiastic putative director for each topic at an early stage, giving him a licence to use persuasion and temptation to tell who will be willing to come, for how long, if the board should sanction the proposal.

So far, this process has led the institute to tackle the difficult problems of physics head-on rather than to seek easy popularity in softer fields. The topic nearest to biology, for example, was a programme on "Spin glasses, computation and neural networks" in 1986. Field theory in all its ramification (quantum gravity included) seems to be the central theme, but there is a sustained interest in the cosmological connection, while condensed-matter physics is strengthening its hold on the institute's attention, no doubt because of Schrieffer's own interest and the presence as a permanent member of J.S.Langer, tempted here from the University of Pennsylvania in 1982 and best known for his treatment of the thermodynamics of aggregation in the days before computer simulation became the rage it is now.

While the counting of published papers and their citations is hardly a sure guide to the quality of people's achievements, perhaps the most vivid proof of this institute's success is the remarkable frequency with which its address turns up in the better physics journals. But the permanent members and the small band of resident postdoctoral fellows have the peculiar advantage of seeing the whole world (or what matters in it) pass along their corridor. "Just stay here long enough" according to one of them, "and you'll have met everybody". He was referring, of course, to the community of theoretical physics.

Santa Barbara is not, of course, the only place with similar objectives. Perhaps the best-known is the Bohr Institute in Copenhagen, now supported under the banner of NORDITA by all Scandanavian governments. The Institut des Hautes Etudes near Paris is another. Santa Barbara would say that they are more like ivory towers than it would wish to be. The closest model of this way of working is the International Institute of Theoretical Physics at Trieste, founded by Abdus Salam at about the same time. The new Indian institute at Pune, directed by J.S.Narlikar, will follow a similar pattern but in the narrower field of cosmology, relativity and matter.

What can be learned from the Santa Barbara experience by those with ambitions to set up similar institutes elsewhere? Theoretical physics, being portable, is an obvious field in which to look for success, but it is clear that this institute owes a great deal to the hinterland on which it has been able to draw. It is difficult to see that it could have done as well if the United States had not been as well supplied with theoreticians.

The other crucial consideration is that the budget (which here now just exceeds $\$ 2$ million a year) should be large and flexible enough to help with travel and lodging costs. This is notoriously the most difficult kind of money to come by, especially on a regular but untied basis. Some of Santa Barbara's support now comes from the National Aernoautics and Space Administration, but Schrieffer is grateful that it is laundered through the National Science Foundation's accounts. And even then, the permanent members of the institute find it necessary to supplement the institute's funds by means of the usual round of grant application. The moral is that, while $\$ 2$ million a year is a sizeable sum, it is not enough to buy a reputation in theoretical physics even in a halcyon climate such as this. John Maddox 